\title{
The climatic impact of food consumption in a representative sample of Irish adults and implications for food and nutrition policy
}

\author{
John J Hyland ${ }^{1}$, Maeve Henchion ${ }^{1}$, Mary McCarthy ${ }^{2}$ and Sinéad N McCarthy ${ }^{1, *}$ \\ 'Department of Agrifood Business and Spatial Analysis, Teagasc Food Research Centre, Ashtown, Dublin 15, \\ Republic of Ireland: ${ }^{2}$ Department of Food Business \& Development, University College Cork, Cork, Republic of Ireland
}

Submitted 1 March 2016: Final revision received 26 July 2016: Accepted 5 August 2016: First published online 26 September 2016

\begin{abstract}
Objective: To evaluate the greenhouse gas emissions (GHGE) associated with the diet of Irish adults.

Design: GHGE were estimated by applying conversion factors to habitual food consumption data taken from the National Adult Nutrition Survey, which was representative of the population. Descriptive analyses were undertaken for GHGE for the total population, as well as accounting for energy misreporting and across categories of sociodemographic and socio-economic factors and tertiles of emissions.

Setting: Republic of Ireland.

Subjects: Adults aged 18-87 years ( $n$ 1500).

Results: The GHGE derived from daily dietary intakes was estimated as $6.5 \mathrm{~kg}$ of $\mathrm{CO}_{2}$ equivalents $\left(\mathrm{CO}_{2} \mathrm{eq}\right)$ per person. Males, younger consumers, those with secondary education and student employment status were associated with significantly higher GHGE. Red meat was the highest contributor to GHGE with $1646 \mathrm{~g} \mathrm{CO}_{2}$ eq arising from a mean intake of $47 \mathrm{~g} / \mathrm{d}$. Dairy and starchy staples were the next largest dietary GHGE sources, with mean daily emissions of $732 \mathrm{~g}$ $\mathrm{CO}_{2} \mathrm{eq}$ and $647 \mathrm{~g} \mathrm{CO}_{2} \mathrm{eq}$, respectively. The lowest emissions were associated with consumption of vegetables, fruits and legumes/pulses/nuts.

Conclusions: Based on profiling using actual food consumption data, it is evident that one single measure is not sufficient and a range of evidence-based mitigation measures with potential to lower emissions throughout the food chain should be considered. The research contributes towards an improved understanding of the climatic impact of the dietary intakes of Irish adults and can serve to inform a sustainability framework to guide action in food and nutrition policy development.
\end{abstract}

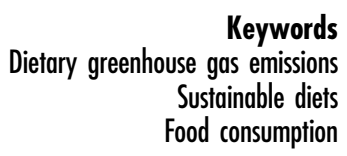

The production and consumption of food have direct impacts on both human health and the environment ${ }^{(1)}$. Agricultural production is ultimately driven by food consumption demands and represents a substantial source of anthropogenic greenhouse gases ${ }^{(2,3)}$. In Ireland, the agricultural sector is one of the largest indigenous industries, with approximately $90 \%$ of the food produced exported to the UK, the EU and other markets. Thus, relative to many other European countries, Ireland is somewhat unusual in that the agricultural sector constitutes the largest proportion $(32 \cdot 3 \%)$ of national greenhouse gas emissions $(\mathrm{GHGE})^{(4)}$. Ireland has its own climate change legislation and is also subject to EU emission reduction targets ${ }^{(5-7)}$. Considering that food consumption strongly influences the climatic impact of the food system ${ }^{(8)}$, achieving mitigation targets may prove challenging without significant changes to diets ${ }^{(9)}$. However, altering diet for climatic reasons may have implications from a public health and nutrition perspective. Unsurprisingly therefore, the FAO recommends giving due consideration to climatic impacts when developing dietary guidelines and policies ${ }^{(10)}$.

The climatic impact of food consumption is measured based on the global warming potential of greenhouse gases generated throughout the food chain. A global warming potential is a relative measure of how much heat, relative to $\mathrm{CO}_{2}$, a greenhouse gas traps in the atmosphere and is expressed in terms of $\mathrm{CO}_{2}$ equivalents $\left(\mathrm{CO}_{2} \mathrm{eq}\right)^{(11)}$. Both activity data (i.e. food consumed) and emission factors (multipliers that convert quantity of foods consumed to GHGE) are required to calculate a carbon footprint of one's diet. Generally, a carbon footprint is 
based on life cycle assessment (LCA), which reflects total $\mathrm{CO}_{2}$ eq generated throughout each stage of the food system $^{(12)}$. Each stage is defined by a system boundary which indicates the point along the food chain at which emissions are assessed and aggregated ${ }^{(13)}$. From this, the final carbon footprint is expressed by a functional unit which can be used to reflect the way in which a product is consumed $^{(14)}$. For instance, emissions associated with dietary patterns are typically expressed in terms of weight of food consumed (i.e. quantity of GHGE per quantity of food consumed) ${ }^{(15)}$.

The largest proportion of the GHGE from food products is generated on-farm, with markedly lower emissions from reprocessing, retail, preparation, consumption and waste $^{(11)}$. The contribution of ruminants towards anthropogenic-induced climate change is particularly relevant as methane, a potent greenhouse gas with a global warming potential twenty-five times that of $\mathrm{CO}_{2}$, is generated on-farm ${ }^{(16-18)}$. For this reason, the carbon footprint of beef and lamb can be as much as forty times greater than that of many fruits and vegetables per gram of food eaten ${ }^{(8,19-22)}$.

\section{Dietary emissions}

The concept of 'sustainable diets' was coined in light of recognition of the need for food to be both nutritious and environmentally considerate. The FAO has defined sustainable diets as 'diets with low environmental impacts which contribute to food and nutrition security and to healthy life for present and future generations. Sustainable diets are protective and respectful of biodiversity and ecosystems, culturally acceptable, accessible, economically fair and affordable; nutritionally adequate, safe and healthy; while optimizing natural and human resources ${ }^{(23)}$. Therefore, diets should not only adhere to nutritional adequacy principles but also environmental and ethical concerns. This represents challenges all along the food chain and especially to those involved in formulating nutritional guidelines ${ }^{(24)}$. The concept of sustainable diets represents an opportunity to successfully advance commitments to achieving emissions targets by reducing dietary emissions ${ }^{(25)}$. To date a range of studies have been undertaken to quantify the GHGE associated with differing dietary patterns and propose recommendations for changes in consumption that are both nutritious and sustainable $e^{(1,15,26)}$

Evidence points to many inherent contradictions which should be considered when developing and implementing sustainable dietary recommendations. In certain studies, modelling scenarios have been used which show that reducing dietary GHGE while ensuring nutritional adequacy is theoretically feasible ${ }^{(27-29)}$. Such studies are theoretical in nature and do not take into consideration the prevailing food consumption patterns of a population or inherent difficulties in changing consumer behaviour.
Conversely, research derived from the French national food consumption data demonstrated that self-selecting diets which are lower in dietary emissions were also lower in nutritional quality when assessed on a nutrient density score rather than per gram of food consumed ${ }^{(30-32)}$. Vieux et al. observed that those who consumed a healthy diet, defined by low energy density, and low intakes of saturated fat, sugar and salt but high nutrient density, had higher $\mathrm{GHGE}^{(31)}$. Meanwhile, Masset et al. also showed that diets with lower than average GHGE tended to be less healthy based on nutrient density scores ${ }^{(32)}$. The relationship of higher intakes of fruits and vegetables with lower GHGE and better health outcomes has also been demonstrated. Scarborough et al. showed a positive relationship between GHGE and the quantity of animalbased foods in a standardised $8368 \mathrm{~kJ}(2000 \mathrm{kcal}) \operatorname{diet}^{(33)}$. Furthermore, that study found that as the quantity of animal-based foods decreased the intake of fruits and vegetables increased; this resulted in higher consumption of fibre and lower consumption of saturated fat ${ }^{(33)}$.

Internationally, there have been numerous assessments of GHGE based on consumption surveys ${ }^{(19,30,34,35)}$. Consumption surveys tend to be favoured as they are often more representative of food intake than other methods which use commodity data to derive consumption $^{(26)}$. However, inherent shortcomings in these data can occur as respondents can be inclined to change their food habits when consumption is recorded or others may not report consumption of various foods ${ }^{(36)}$. 'Energy misreporters' refers to individuals whose food intake is insufficient to sustain their $\mathrm{BMR}^{(37,38)}$. Only in some instances are outliers or misreporters in consumption data accounted for when reporting dietary emissions ${ }^{(30)}$. However, interpreting dietary emissions using consumption data is not without other challenges. For example, per capita dietary emissions in the UK have been estimated to range between 5.7 and $8 \cdot 8 \mathrm{~kg} \mathrm{CO}_{2} \mathrm{eq} / \mathrm{d}^{(19,22,34)}$. Deviations between reported UK dietary emissions are primarily a result of methodological differences, most notably the distinct system boundaries adopted, emission factors used and food consumption data assessed by each respective study. Methodological issues can consequently make direct comparisons between studies difficult. It is therefore important that the methods used to attain dietary emissions are explicitly stated as contrasting approaches can greatly influence overall findings.

To date no detailed analysis has been undertaken to determine the GHGE associated with food consumption in a national representative sample of Irish adults. Therefore, the aim of the present study was to take account of the aforementioned methodological considerations to determine the levels of and contributors to GHGE in the Irish diet. This was achieved by identifying a range of previously estimated emission factors from the literature which were applicable to an Irish context. The study adds to the current literature in that it uses representative food 
consumption data, accounts for energy misreporters, while also adopting emission factors that include emissions induced post-retail. It is hoped that in doing so a best possible estimate of Irish dietary emissions can be calculated. Determining the GHGE of nationally representative dietary patterns can serve to inform a framework to guide action in public health nutrition towards sustainable diets. Thus, the findings of the present study can assist in developing policies and practices that address dietary factors contributing to climate change.

\section{Methodology}

\section{Food consumption data}

Food consumption data from the National Adult Nutrition Survey (NANS) of Ireland were used ${ }^{(39)}$. The survey has been described previously in detail by Naughton et al. ${ }^{(40)}$. In brief, NANS was conducted from 2008 to 2010 on 1500 Irish adults ranging in age from 18 to 87 years and is representative of the Irish population with respect to age, gender, geographic location, marital status and social class when compared with the national census data from 2006, as illustrated in Table 1. The demographic features of the NANS have been shown to be representative of Irish adults with respect to age, gender, social class and geographical location when compared to census data ${ }^{(39)}$.

Ethical approval for the survey was granted by the University College Cork Clinical Research Ethics Committee of the Cork Teaching Hospitals and written informed consent was obtained from study participants. A semiweighed food diary was used to collect data on food and beverage intake on four consecutive days. The days of data collection were different for each participant to ensure that all weekdays and weekend days were equally recorded. Participants were instructed to provide detailed information on the amount and types of all foods and beverages consumed over the recording period and where applicable, the cooking methods, brand names of the foods, and details of recipes and leftovers. The Weighted Intake Software Program (WISP; Tinuviel Software, Warrington, UK) was used to analyse the food intake data to generate nutrient intakes. Each of the 2552 different foods consumed during the survey was assigned to one of sixty-seven food groups.

\section{Allocating emission factors}

At the time of the present study a comprehensive GHGE profile of the foods consumed in Ireland was unavailable. Therefore, GHGE factors from multiple sources in the literature were reviewed and those most applicable to an Irish context were used as detailed in online 'Supplementary material 1'. The emission factors assigned to the food groups from the NANS are drawn primarily from studies in the $\mathrm{UK}^{(22)}$ and the USA ${ }^{(41)}$, where both carried out extensive meta-analyses of GHGE associated with food consumption. The system boundary at which emission factors are assessed is defined to include emissions associated with food production, packing, distribution, storage/refrigeration, transportation, food handling/preparation and consumer waste ${ }^{(22,41,42)}$. Emission factors related exclusively to Irish dairy produce were previously generated. These factors were used for the present study as the vast majority of dairy produce consumed in Ireland is produced domestically ${ }^{(43)}$. However, the available emission factors relating to Irish dairy did not include emissions associated with the LCA system boundaries from retail to waste. Therefore, the same approach as in Green et al. was adopted when accounting for these post-retail emissions $^{(22)}$. Emissions to include these boundaries were subsequently estimated to be an additional $18 \%$ for milk and milk products, and 14\% for butter; with $9 \%$ added to all dairy products to account for travel and

Table 1 The sociodemographic profile of National Adult Nutrition Survey (NANS) participants in comparison with national Irish census of population data ( $n 1500$ denotes full NANS sample; $n 960$ denotes the NANS sample with energy misreporters removed)

\begin{tabular}{|c|c|c|c|c|}
\hline & & $\begin{array}{c}2006 \\
\text { Census }^{*}\end{array}$ & $\begin{array}{l}\text { NANS } \\
(n 1500)\end{array}$ & $\begin{array}{l}\text { NANS } \\
(n 960)\end{array}$ \\
\hline \multirow[t]{2}{*}{ Gender (\%) } & Men & 50 & 49 & 49 \\
\hline & Women & 50 & 51 & 51 \\
\hline \multirow[t]{4}{*}{ Age group (\%) } & 18-35 years & 35 & 35 & 38 \\
\hline & $26-50$ years & 29 & 29 & 31 \\
\hline & $51-64$ years & 21 & 20 & 20 \\
\hline & $65+$ years & 15 & 15 & 11 \\
\hline \multirow[t]{3}{*}{ Marital status (\%) } & Single & 38 & 32 & 35 \\
\hline & Married/living with partner & 51 & 58 & 58 \\
\hline & Widowed/separated/divorced & 11 & 9 & 7 \\
\hline \multirow[t]{2}{*}{ Location (\%) } & Rural & 39 & 30 & 29 \\
\hline & Urban & 61 & 70 & 71 \\
\hline \multirow[t]{4}{*}{ Social class (\%) } & Professional/managerial & 33 & 46 & 49 \\
\hline & Non-manual & 17 & 18 & 17 \\
\hline & Un/semi/skilled/manual & 32 & 21 & 19 \\
\hline & Occupation unknown/students & 18 & 15 & 15 \\
\hline
\end{tabular}

*Irish Census data freely available from the Central Statistics Office, Ireland. 
refrigeration ${ }^{(22,38)}$. For the purpose of the present study dietary emissions can be defined as the quantity of daily GHGE generated by the consumption of food by an individual.

\section{Analyses}

The conversion factors for emissions were applied to the disaggregated sixty-seven NANS food groups and these were then further aggregated into sixteen food groups of similar food type characteristics. For instance, the food group labelled 'Red meat' comprised 'beef and veal', 'lamb', 'burgers', 'offal and offal dishes' derived from ruminants, the ruminant proportion of 'red meat dishes', along with the ruminant proportion of 'lamb, pork, and bacon dishes' from the NANS. Details of how each of the groups was aggregated are presented in online 'Supplementary material 1'. Of the 1500 participants, 540 were classified as energy misreporters as they had a ratio of energy intake to BMR that was either missing or did not fit into the recommended range of confidence limits of 1.02$2 \cdot 35^{(37,38)}$. To highlight the impact of energy misreporting on dietary emissions, some analyses focused on dietary emissions associated with food groups included the whole sample ( $n$ 1500) as well as some which only included representative energy reporters ( $n$ 960). Emissions intensity was calculated as the quantity of GHGE in kilograms generated per energy provided in megajoules $\left(\mathrm{kg} \mathrm{CO}_{2} \mathrm{eq} /\right.$ $\mathrm{MJ})^{(44)}$. Three sensitivity analyses were carried out (see online 'Supplementary material 2'). First, the proportion of the meat component of composite dishes was increased from 35 to $50 \%$. Second, US emission factors were favoured where possible over those adopted from the UK. Third, emission factors for animal products were reduced by $20 \%$.

Statistical analyses were carried out using the statistical software package PASW Statistics Version 18.0. The size of the data set was sufficiently large to apply the Central Limit Theorem so that normality could be assumed ${ }^{(45)}$. Independent $t$ tests and ANOVA tests were used to determine significant differences. Levene's test of homogeneity was used to inspect equality of variance for parametric tests. If homogeneity was confirmed, ANOVA was carried out with Bonferroni corrections; otherwise ANOVA was performed using the Welch test followed by the Games-Howell post hoc test. An $\alpha$ level of $<0.05$ was used to determine statistical significance.

Sociodemographic profiles of food consumption, dietary emissions and emissions intensity patterns were first assessed. Subsequent analysis was carried out to determine the relationship between GHGE and food consumption for the total population and excluding energy misreporters. Thereafter, dietary emissions and energy for each of the food groups were evaluated based on their relative (percentage) daily contribution towards total daily GHGE and energy intake. Participants were also classified into gender-specific groups of low, moderate and high emitters in terms of total dietary emissions. To account for gender differences in food intake and associated GHGE, tertile values were calculated specifically for men and for women separately and then combined into the gender-specific tertiles. Hence each tertile contained an equal proportion of males and females.

\section{Results}

\section{Sociodemographic and socio-economic profiles of food consumption and dietary emissions}

Table 2 presents differences in dietary GHGE, food intake, energy intake and emissions intensity of food consumption across sociodemographic and socio-economic categories. With the exception of location, significant differences in dietary emissions were observed for all categories. Males, younger consumers, those with secondary education and student employment status were associated with significantly higher GHGE. Similar patterns were also observed for food and energy intakes, except for education where no significant differences were observed. However, when emissions were expressed as intensity $\left(\mathrm{CO}_{2} \mathrm{eq} / \mathrm{MJ}\right.$ per $\left.\mathrm{d}\right)$, significant differences were observed only for gender whereby men had significantly higher emissions intensity compared with women. Many of these differences were explained by differences in food intakes; for example, men consumed significantly more meat than women, and younger groups consumed significantly more burgers and alcohol (data not shown).

\section{Relationship between food consumption and emissions}

Food consumption and its associated dietary GHGE are shown in Table 3 for both the total population and a sample excluding misreporters ( $n$ 960). Mean daily GHGE associated with food consumption was $6532 \mathrm{~g} \mathrm{CO}_{2} \mathrm{eq}$ for representative energy reporters and $5992 \mathrm{~g} \mathrm{CO}_{2} \mathrm{eq}$ for the total population when energy misreporters were included in the analysis. The inclusion of energy misreporters in the sample resulted in lower daily emissions from all of the food groups. Representative energy reporters consumed a daily total mean food intake of $3005 \mathrm{~g}$. The food group with the highest intake was starchy staples with $387 \mathrm{~g}$ consumed daily, which accounted for $647 \mathrm{~g} \mathrm{CO}_{2}$ eq. The highest beverage group intake was $1234 \mathrm{~g} / \mathrm{d}$ for 'other beverages' which include tea, coffee, water, etc. and accounted for $402 \mathrm{~g} \mathrm{CO}_{2} \mathrm{eq} / \mathrm{d}$. The highest daily contributor to GHGE at $1646 \mathrm{~g} \mathrm{CO}_{2} \mathrm{eq}$ was red meat, arising from a mean intake of $47 \mathrm{~g} / \mathrm{d}$. Dairy $(289 \mathrm{~g} / \mathrm{d})$ and starchy staples $(387 \mathrm{~g} / \mathrm{d})$ were the next largest dietary GHGE sources, with mean daily emissions of $732 \mathrm{~g} \mathrm{CO} 2 \mathrm{eq}$ and $647 \mathrm{~g} \mathrm{CO}_{2} \mathrm{eq}$, respectively. The lowest emissions were associated with consumption of vegetables, fruits and legumes/pulses/nuts. 
Table 2 Mean daily greenhouse gas emissions (GHGE), food intakes, energy intakes and emissions intensities, across sociodemographic and socio-economic categories, for the sample of nationally representative Irish adults excluding energy misreporters $(n 960)$

\begin{tabular}{|c|c|c|c|c|c|c|c|c|c|}
\hline & \multirow[b]{2}{*}{$n$} & \multicolumn{2}{|c|}{$\begin{array}{c}\mathrm{GHGE} \\
\text { (g CO } \mathrm{g}_{2} \text { eq/d) }\end{array}$} & \multicolumn{2}{|c|}{$\begin{array}{l}\text { Food intake } \\
(\mathrm{g} / \mathrm{d})\end{array}$} & \multicolumn{2}{|c|}{$\begin{array}{l}\text { Energy intake } \\
(\mathrm{MJ} / \mathrm{d})\end{array}$} & \multicolumn{2}{|c|}{$\begin{array}{l}\text { Emissions intensity } \\
\left(\mathrm{kg} \mathrm{CO} \mathrm{CO}_{2} \mathrm{eq} / \mathrm{MJ} \text { per d) }\right.\end{array}$} \\
\hline & & Mean & SD & Mean & SD & Mean & SD & Mean & SD \\
\hline Total & & 6532 & 2337 & 3005 & 967 & 9 & 2 & 1 & 0 \\
\hline \multicolumn{10}{|l|}{ Gender } \\
\hline Male & 470 & $7850^{\mathrm{a}}$ & 2345 & $3339^{a}$ & 1031 & $11^{\mathrm{a}}$ & 2 & $1^{\mathrm{a}}$ & 0 \\
\hline Female & 490 & $5268^{b}$ & 1471 & $2685^{\mathrm{b}}$ & 777 & $8^{\mathrm{b}}$ & 1 & $1^{\mathrm{b}}$ & 0 \\
\hline \multicolumn{10}{|l|}{ Age group } \\
\hline 18-35 years & 364 & $7096^{a}$ & 2624 & $3166^{a}$ & 1095 & $10^{\mathrm{a}}$ & 3 & 1 & 0 \\
\hline $36-50$ years & 299 & $6299^{b}$ & 2228 & $2956^{\mathrm{b}}$ & 930 & $9^{b}$ & 2 & 1 & 0 \\
\hline $51-64$ years & 189 & $6147^{b}$ & 1889 & $2917^{b}$ & 766 & $9^{b, c}$ & 2 & 1 & 0 \\
\hline $65+$ years & 108 & $5953^{b}$ & 1913 & $2751^{b}$ & 835 & $8^{\mathrm{C}}$ & 2 & 1 & 0 \\
\hline \multicolumn{10}{|l|}{ Location } \\
\hline Country/village & 282 & 6465 & 2172 & 2927 & 896 & 9 & 2 & 1 & 0 \\
\hline Town & 373 & 6633 & 2464 & 3064 & 1035 & 10 & 3 & 1 & 0 \\
\hline City & 305 & 6472 & 2328 & 3005 & 942 & 9 & 2 & 1 & 0 \\
\hline \multicolumn{10}{|l|}{ Education } \\
\hline Primary & 65 & $6562^{a, b}$ & 2034 & 2853 & 1072 & $9^{a, b}$ & 2 & 1 & 0 \\
\hline Intermediate & 184 & $6630^{a, b}$ & 2302 & 2933 & 905 & $9^{a, b}$ & 2 & 1 & 0 \\
\hline Secondary & 227 & $7024^{\mathrm{b}}$ & 2778 & 3057 & 1058 & $10^{\mathrm{b}}$ & 3 & 1 & 0 \\
\hline Tertiary & 475 & $6232^{\mathrm{a}}$ & 2048 & 3029 & 932 & $9^{a, c}$ & 2 & 1 & 0 \\
\hline \multicolumn{10}{|l|}{ Employment status } \\
\hline Working for payment & 548 & $6508^{a}$ & 2197 & $3014^{a}$ & 923 & $9^{a}$ & 2 & 1 & 0 \\
\hline Working from home & 86 & $5305^{b}$ & 1361 & $2647^{b}$ & 764 & $8^{\mathrm{b}}$ & 2 & 1 & 0 \\
\hline Not working & 197 & $6285^{\mathrm{a}}$ & 2250 & $2944^{\mathrm{a}}$ & 970 & $9^{c}$ & 2 & 1 & 0 \\
\hline Student & 129 & $7832^{c}$ & 2913 & $3300^{c}$ & 1166 & $11^{\mathrm{d}}$ & 3 & 1 & 0 \\
\hline
\end{tabular}

$\mathrm{CO}_{2}$ eq, $\mathrm{CO}_{2}$ equivalents.

${ }_{a, b, c, d}$ Mean values within a column (within sociodemographic and socio-economic categories) with unlike superscript letters were significantly different $(P<0.05)$.

Table 3 Mean daily food intakes and associated dietary greenhouse gas emissions (GHGE) for the total sample of nationally representative Irish adults ( $n 1500)$ and excluding energy misreporters ( $n 960)$

\begin{tabular}{|c|c|c|c|c|c|c|c|c|}
\hline & \multicolumn{4}{|c|}{ Food intake $(\mathrm{g} / \mathrm{d})$} & \multicolumn{4}{|c|}{ GHGE $\left(\mathrm{g} \mathrm{CO}_{2} \mathrm{eq} / \mathrm{d}\right)$} \\
\hline & \multicolumn{2}{|c|}{$n 960$} & \multicolumn{2}{|c|}{$n 1500$} & \multicolumn{2}{|c|}{$n 960$} & \multicolumn{2}{|c|}{$n 1500$} \\
\hline & Mean & SD & Mean & SD & Mean & SD & Mean & SD \\
\hline Total & 3005 & 967 & 2753 & 1013 & 6532 & 2337 & 5992 & 2394 \\
\hline Starchy staples & 387 & 147 & 360 & 147 & 647 & 229 & 599 & 233 \\
\hline Dairy & 289 & 212 & 261 & 200 & 732 & 477 & 661 & 459 \\
\hline Vegetables & 80 & 65 & 77 & 64 & 71 & 78 & 69 & 75 \\
\hline Fruit & 105 & 118 & 97 & 114 & 75 & 83 & 68 & 79 \\
\hline Legumes/pulses/nuts & 29 & 35 & 27 & 34 & 49 & 58 & 46 & 56 \\
\hline Red meat & 47 & 44 & 45 & 43 & 1646 & 1539 & 1558 & 1509 \\
\hline Eggs/poultry/pork & 85 & 55 & 81 & 54 & 584 & 383 & 555 & 374 \\
\hline Fish & 26 & 37 & 26 & 36 & 249 & 347 & 244 & 341 \\
\hline Processed meat & 33 & 41 & 29 & 39 & 303 & 380 & 274 & 361 \\
\hline Savoury snacks & 44 & 61 & 37 & 56 & 221 & 330 & 189 & 302 \\
\hline High-sugar snacks & 94 & 69 & 82 & 68 & 267 & 198 & 234 & 200 \\
\hline Fats/oils & 22 & 17 & 20 & 17 & 281 & 319 & 259 & 311 \\
\hline Carbonated beverages & 108 & 185 & 93 & 168 & 217 & 370 & 185 & 337 \\
\hline Other beverages & 1234 & 659 & 1157 & 661 & 402 & 324 & 364 & 307 \\
\hline Alcoholic beverages & 356 & 612 & 300 & 554 & 533 & 917 & 451 & 831 \\
\hline Miscellaneous & 66 & 70 & 61 & 68 & 257 & 271 & 237 & 267 \\
\hline
\end{tabular}

$\mathrm{CO}_{2} \mathrm{eq}, \mathrm{CO}_{2}$ equivalents.

Table 4 profiles the percentage contribution and ranking of each of the food groups in terms of contribution to both emissions and energy intake, as well as the ratio of emissions generated relative to the energy intake derived from the food group. Red meat was consumed by more than three-quarters of the population and was associated with $22.3 \%$ of daily GHGE while providing just over $4 \%$ of daily energy intake (Table 4 ). Therefore, the red meat food group generated high daily dietary emissions while providing a relatively low proportion of dietary 
Table 4 Food groups' ranking in terms of contribution to daily dietary greenhouse gas emissions (GHGE), daily energy intake (MJ) and the ratio of daily emissions to energy provided by the food group (GHGE:MJ) for the nationally representative sample of Irish adults excluding energy misreporters $(n$ 960)

\begin{tabular}{|c|c|c|c|c|c|c|}
\hline Rank GHGE & Rank MJ & Food group & $\% G H G E$ & $\% \mathrm{MJ}$ & GHGE:MJ & $\%$ Consumers \\
\hline 1 & 7 & Red meat & $22 \cdot 3$ & 4.4 & $5 \cdot 1$ & 77.8 \\
\hline 2 & 3 & Dairy & $12 \cdot 0$ & $11 \cdot 0$ & $1 \cdot 1$ & 99.0 \\
\hline 3 & 1 & Starchy staples & $10 \cdot 6$ & 29.7 & 0.4 & $100 \cdot 0$ \\
\hline 4 & 4 & Eggs/poultry/pork & 9.5 & 6.9 & 1.4 & $97 \cdot 6$ \\
\hline 5 & 5 & Alcoholic beverages & $6 \cdot 9$ & $6 \cdot 2$ & $1 \cdot 1$ & 64.0 \\
\hline 6 & 15 & Other beverages & $6 \cdot 5$ & 1.4 & 4.6 & $100 \cdot 0$ \\
\hline 7 & 8 & Processed meat & 4.6 & 3.9 & $1 \cdot 2$ & $64 \cdot 2$ \\
\hline 8 & 2 & High-sugar snacks & 4.6 & $14 \cdot 6$ & 0.3 & 96.4 \\
\hline 9 & 9 & Fats/oils & 4.5 & 3.6 & $1 \cdot 3$ & $95 \cdot 1$ \\
\hline 10 & 12 & Fish & 4.2 & $2 \cdot 1$ & $2 \cdot 0$ & $53 \cdot 1$ \\
\hline 11 & 10 & Miscellaneous & 4.2 & 3.0 & 1.4 & $97 \cdot 1$ \\
\hline 12 & 6 & Savoury snacks & 3.5 & 5.4 & 0.6 & 71.5 \\
\hline 13 & 14 & Carbonated beverages & $3 \cdot 1$ & 1.6 & 1.9 & 55.4 \\
\hline 14 & 11 & Fruit & 1.3 & $2 \cdot 8$ & 0.5 & $76 \cdot 7$ \\
\hline 15 & 16 & Vegetables & $1 \cdot 2$ & 1.3 & 0.9 & $92 \cdot 3$ \\
\hline 16 & 13 & Legumes/pulses/nuts & 0.8 & $2 \cdot 1$ & 0.4 & $80 \cdot 3$ \\
\hline
\end{tabular}

Table 5 Mean daily intake of each food group and associated greenhouse gas emissions (GHGE) across tertiles of low, moderate and high emitters for the nationally representative sample of Irish adults excluding energy misreporters ( $n$ 960)

\begin{tabular}{|c|c|c|c|c|c|c|c|c|c|c|c|c|}
\hline & \multicolumn{6}{|c|}{ Food intake $(\mathrm{g})$} & \multicolumn{6}{|c|}{ GHGE $\left(\mathrm{g} \mathrm{CO}_{2} \mathrm{eq} / \mathrm{g}\right)$} \\
\hline & \multicolumn{2}{|c|}{ Low (n 320) } & \multicolumn{2}{|c|}{ Moderate ( $n$ 321) } & \multicolumn{2}{|c|}{ High (n 319) } & \multicolumn{2}{|c|}{ Low (n 320) } & \multicolumn{2}{|c|}{ Moderate ( $n$ 321) } & \multicolumn{2}{|c|}{ High (n 319) } \\
\hline & Mean & SD & Mean & SD & Mean & SD & Mean & SD & Mean & SD & Mean & SD \\
\hline Total & $2601^{a}$ & 743 & $2944^{\mathrm{b}}$ & 856 & $3471^{\mathrm{C}}$ & 1069 & $4676^{\mathrm{a}}$ & 1074 & $6262^{b}$ & 1295 & $8667^{c}$ & 2348 \\
\hline Starchy staples & 373 & 159 & 388 & 142 & 399 & 141 & $600^{\mathrm{a}}$ & 214 & $650^{\mathrm{b}}$ & 232 & $690^{\mathrm{b}}$ & 232 \\
\hline Dairy & $262^{\mathrm{a}}$ & 179 & $284^{a, b}$ & 197 & $323^{\mathrm{b}}$ & 249 & $659^{a}$ & 401 & $724^{a, b}$ & 465 & $815^{\mathrm{b}}$ & 542 \\
\hline Vegetables & 77 & 61 & 83 & 70 & 80 & 63 & 70 & 71 & 70 & 80 & 73 & 82 \\
\hline Fruit & $114^{\mathrm{a}}$ & 123 & $114^{\mathrm{a}}$ & 124 & $87^{\mathrm{b}}$ & 102 & $80^{\mathrm{a}}$ & 81 & $84^{\mathrm{a}}$ & 93 & $61^{\mathrm{b}}$ & 71 \\
\hline Legumes/pulses/nuts & 28 & 33 & 30 & 34 & 29 & 37 & 48 & 55 & 52 & 57 & 48 & 61 \\
\hline Red meat & $17^{a}$ & 21 & $41^{\mathrm{b}}$ & 31 & $84^{c}$ & 46 & $598^{\mathrm{a}}$ & 732 & $1410^{\mathrm{b}}$ & 1070 & $2934^{\mathrm{C}}$ & 1610 \\
\hline Eggs/poultry/pork & 83 & 54 & 88 & 53 & 85 & 59 & 571 & 382 & 597 & 366 & 582 & 401 \\
\hline Fish & 24 & 32 & 29 & 37 & 27 & 41 & 226 & 301 & 269 & 352 & 251 & 382 \\
\hline Processed meat & $26^{a}$ & 37 & $31^{a}$ & 38 & $41^{\mathrm{b}}$ & 45 & $241^{a}$ & 344 & $289^{a}$ & 358 & $378^{\mathrm{b}}$ & 423 \\
\hline Savoury snacks & $36^{\mathrm{a}}$ & 50 & $44^{\mathrm{a}, \mathrm{b}}$ & 63 & $51^{\mathrm{b}, \mathrm{c}}$ & 69 & $182^{\mathrm{a}}$ & 271 & $222^{a, b}$ & 334 & $258^{\mathrm{b}}$ & 374 \\
\hline High sugar snacks & $99^{a}$ & 65 & $103^{a}$ & 79 & $81^{\mathrm{b}}$ & 59 & $278^{a}$ & 185 & $292^{\mathrm{a}}$ & 227 & $231^{\mathrm{b}}$ & 174 \\
\hline Fats/oils & $20^{\mathrm{a}}$ & 15 & $22^{a, b}$ & 17 & $24^{\mathrm{b}}$ & 18 & 274 & 310 & 272 & 324 & 296 & 323 \\
\hline Carbonated beverages & $52^{\mathrm{a}}$ & 102 & $101^{\mathrm{b}}$ & 173 & $172^{\mathrm{c}}$ & 235 & $105^{a}$ & 205 & $201^{\mathrm{b}}$ & 347 & $344^{\mathrm{C}}$ & 471 \\
\hline Other beverages & 1198 & 614 & 1222 & 654 & 1283 & 704 & $333^{\mathrm{a}}$ & 262 & $410^{\mathrm{b}}$ & 328 & $465^{\mathrm{b}}$ & 361 \\
\hline Alcoholic beverages & $140^{\mathrm{a}}$ & 252 & $295^{\mathrm{b}}$ & 445 & $632^{\mathrm{c}}$ & 859 & $211^{a}$ & 378 & $443^{b}$ & 668 & $948^{\mathrm{C}}$ & 1289 \\
\hline Miscellaneous & $51^{a}$ & 57 & $71^{\mathrm{b}}$ & 75 & $75^{\mathrm{b}}$ & 73 & $201^{a}$ & 223 & $277^{\mathrm{b}}$ & 291 & $293^{b}$ & 286 \\
\hline
\end{tabular}

$\mathrm{CO}_{2} \mathrm{eq}, \mathrm{CO}_{2}$ equivalents.

${ }^{\text {a,b.c }}$ Mean values within a row (across food intake or GHGE tertiles) with unlike superscript letters were significantly different $(P<0.05)$.

energy, with a GHGE:MJ of 5·1:1. Dairy followed as being the next largest GHGE source but, unlike red meat, its GHGE:MJ was nearly proportionate (1-1:1). Starchy staples were the highest energy source, providing almost $30 \%$ of overall energy intake; they were also the third highest contributor to GHGE at 10.6\%. High-sugar snacks were the second highest source of energy intake at $14.6 \%$ but scored lowest in terms of their GHGE:MJ $(0 \cdot 3: 1)$.

\section{Classification of low, moderate and high emitters}

To further profile the differences in GHGE, tertile analysis was undertaken to determine low, moderate and high dietary emissions. Men and women were categorised separately to account for gender differences in food intake and subsequent dietary emissions. The total sample was then classified into three equal groups of low, moderate and high emitters in terms of their total dietary emissions. Table 5 presents the contribution of each food group in respect of GHGE and daily intake across the tertiles of low, medium and high GHGE emitters.

Total dietary emissions and total food intake increased significantly across increasing tertile $(P<0 \cdot 05)$. Those categorised as high emitters had almost twice the GHGE associated with food consumption than their low emitter peers. Dairy, followed by starchy staples, were the largest contributors to emissions for the low emitter tertile. 
Red meat followed by alcoholic beverages were the largest sources of GHGE for moderate and high emitters. Significant differences were observed across all three groups in both dietary emissions and intakes of red meat, carbonated beverages and alcoholic beverages. No significant differences in dietary emissions were observed between emitters for many food groups; namely, vegetables, legumes/pulses/nuts, eggs/poultry/pork, fish and fats/oils.

\section{Discussion}

Research concerning the deleterious climatic impact of the food system generally relies on typified diets or diets based on average food consumption patterns, thereby not capturing the diversity observed across a representative sample of the population ${ }^{(26)}$. In many studies, dietary emissions are based on consumption-level data from published data (food consumed) ${ }^{(21,29-31,46-48)}$ or GHGE from agricultural commodities ${ }^{(49-52)}$. It has been argued that food consumption surveys provide a more realistic distribution of dietary intakes across societal demographics $^{(26)}$. However, when possible, energy misreporters should be accounted for in analyses to allow for a more realistic interpretation of results ${ }^{(30)}$. This is frequently overlooked in many studies and may result in less accurate and lower reported emission levels. The considerations outlined highlight the notable challenges in making direct and meaningful comparisons between studies as no agreed methodology exists to determine GHGE associated with food consumption. It also highlights the need for harmonisation of national population analysis of dietary GHGE outputs, with the need to be consistent in data type (commodity $v$. consumption), accounting for energy misreporting, as well as using conversion factors with the same system boundaries.

Dietary emissions were estimated in the present study to be $6.5 \mathrm{~kg} \mathrm{CO} 2 \mathrm{eq} / \mathrm{d}$ for a representative sample of the Irish population. Every attempt has been made to calculate as accurately as possible the GHGE associated with food consumption by using full LCA while also accounting for misreporters. Tukker et al. ${ }^{(28)}$ used food balance sheets from the FAO to estimate $7 \cdot 1 \mathrm{~kg} \mathrm{CO} 2 \mathrm{eq} / \mathrm{d}$ as the average GHGE associated with food consumption in the EU. Although the method used by Tukker et al. overestimates per capita consumption, it is an accurate procedure for calculating food-related environmental impacts such as dietary emissions ${ }^{(26)}$. Therefore, it would be reasonable to conclude that at the very least emissions related to food consumption in Ireland are comparable to those across the EU.

Comparability between international and national studies can be difficult due to the varying types of data source used and/or differences such as system boundaries in the emission factors adopted. Researchers from the $\mathrm{UK}^{(19,22,34)}$, France ${ }^{(30)}$ and the Netherlands ${ }^{(35)}$ have obtained dietary data from similar national nutritional surveys as NANS and provide useful comparisons. What is more, Ireland, France, the Netherlands and the UK are comparable in that they share diets that are characterised by low ratio of vegetal to animal energy, high intake of animal fats, and relatively low intakes of cereals and vegetables $^{(28)}$. Various studies have approximated UK dietary emissions as $5 \cdot 7^{(22)}, 7 \cdot 3^{(19)}$ and $8 \cdot 8 \mathrm{~kg} \mathrm{CO} 2 \mathrm{eq} / \mathrm{d}^{(34)}$. Some of the differences in UK estimates can be attributed to the differences in system boundaries, the particular wave of the UK national consumption survey used, emission factors adopted, and whether the study includes children as well as adults. French and Dutch adult dietary emissions have been reported as $4.2 \mathrm{~kg} \quad \mathrm{CO}_{2} \mathrm{eq} / \mathrm{d}^{(30)}$ and $4.3 \mathrm{~kg} \mathrm{CO}_{2} \mathrm{eq} / \mathrm{d}^{(35)}$, respectively. The omission of post-retail emissions and emissions associated with waste may partially explain the higher emission profile of Ireland in comparison to France ${ }^{(30)}$. Furthermore, meat consumption for adults in the French dietary survey used to derive food consumption was $35 \%$ lower than that of the NANS, which would have greatly influenced overall GHGE $^{(53)}$. Dutch dietary emissions were also lower than those observed in Ireland; although Dutch emission factors considered GHGE associated with food waste, energy misreporters were not accounted for in the analysis $^{(35)}$. Indeed, the authors suggested that dietary emissions were underestimated by a similar order of magnitude $(15 \%)$ to the proportion of energy underreporters observed the study ${ }^{(35)}$. Additionally, Dutch meat consumption was $44 \%$ lower than observed in Ireland ${ }^{(54)}$. However, the emission factors applied to meat were lower for both the French and Dutch studies, which may further contribute to their lower overall dietary emissions compared with those of Ireland.

The majority of emission factors used in the present study were those used by Green et al; ; in their study, UK dietary emissions for adults were estimated at $5.7 \mathrm{~kg}$ $\mathrm{CO}_{2} \mathrm{eq} / \mathrm{d}^{(22)}$. However, the UK estimates did not account for energy misreporting; hence their findings were broadly similar to those observed herein of $6 \cdot 0 \mathrm{~kg} \mathrm{CO} 2 \mathrm{eq} / \mathrm{d}$ when the total population including energy misreporters was considered. Meat consumption was 10\% higher in Ireland than observed by Green et al. and may be one of the many factors which may explain why their reported GHGE were slightly lower. A smaller number of emission factors were obtained from Heller and Keoleian and they estimated daily average GHGE in the USA at $5.0 \mathrm{~kg} \mathrm{CO}_{2} \mathrm{eq} / \mathrm{d}$ using commodity data rather than habitual data ${ }^{(41)}$. A sensitivity analysis revealed that Irish dietary emissions were in line with US estimates when using as many of their emission factors as possible (see online 'Supplementary material 2', Table S1).

Differences in GHGE across sociodemographic and socio-economic groups were mostly influenced by the quantity of food consumed. With the exception of gender, the emission intensity of diets (GHGE/MJ) was not 
significantly different across the sociodemographic profiles. Previous research on adult Irish men has shown that they use dietary choices to express masculinity, which can influence a preference for certain foods such as meat ${ }^{(55)}$. Women, on the other hand, often restrict food intake, therefore not eating as much and not consuming meat in the same quantities as men ${ }^{(56)}$. Hence, male dietary preferences may explain the difference observed in both the emission intensity of diets and the variation in dietary emissions between genders. Significant differences in dietary emissions were also observed according to age. Those aged 18-35 years consumed higher quantities of unhealthy foods such as processed meats and alcohol, which leads to overall higher dietary emissions when compared with other age groups. Indeed, other studies have also noted the unhealthy eating patterns of young adults $^{(57,58)}$. Therefore, those aged $18-35$ years failed to adhere to both the environmental and nutritional aspects of a sustainable diet ${ }^{(23)}$. Foods of animal sources contributed most towards GHGE, with red meat responsible for the greatest proportion of Irish dietary emissions. Furthermore, red meat had the highest ratio of GHGE per MJ of energy provided. Higher intakes of animal-based foods were noted in high emitter tertiles. However, the tertiles were not indicative of the complexities and underlying structure of dietary patterns as only a single variable (total dietary emissions) was used for quantile classification.

Foods of animal origin provide many beneficial micronutrients and their high content of essential amino acids and micronutrients should not be overlooked when formulating dietary recommendations that consider both nutrition and $\mathrm{GHGE}^{(59)}$. Clearly, tensions exist in balancing the environmental and nutritional facets of food consumption. It is suggested that to achieve sustainability and public health objectives a transition to a less meat-based diet is required ${ }^{(24)}$. In an effort to address this issue many non-government organisations traditionally favoured climate change messages which ask for modest reductions of meat and encourage consumption of ruminant meat derived from grass-fed systems ${ }^{(60)}$. Recently nongovernment organisations such as the World Resource Institute and Chatham House have been more uncompromising and both have called for a reduction in consumption of animal-based foods ${ }^{(61,62)}$. Research from Tom et al. ${ }^{(63)}$ suggests that per kilojoule, production of vegetables requires more water than meat. Attention should therefore be paid to the potential swapping of one environmental concern for another when developing recommendations to reduce dietary emissions ${ }^{(63)}$. However, the European food system is very different to that which exists in the USA. While Meier and Christen identified that blue water needs were higher for vegan and vegetarian diets in Germany ${ }^{(64)}$, Vanham and co-workers found that the overall water footprint of vegetarian diets was lower than that of other dietary patterns in separate studies of the $\mathrm{EU}^{(65)}$ and Austria ${ }^{(66)}$. Consideration is consequently advised when assessing the sustainability of diets as the climatic impact is only one facet of wider environmental concerns.

While vegan and vegetarian diets can substantially reduce dietary emissions, partial replacement of meat could potentially induce higher climatic effects if the substituted food groups are higher in GHGE than those being displaced (i.e. if chicken was substituted for cheese $)^{(67)}$. Careful consideration is therefore required when formulating health recommendations based on environmental concerns. To provide more holistic assessments, it has been proposed that the sustainability of alternative diets is based upon nutrient and energy contents $^{(32)}$. Hypothetically meat can be replaced by plant-based substitutes but an appreciation of the nutritional equivalency of the replacement food is necessary ${ }^{(68)}$. Replacing the energy and protein attained from average beef consumption could be compensated by the consumption of bean varieties, which leads to GHGE reductions (see online 'Supplementary material 2', Table S2). However, the size of the reduction in GHGE is dependent on the quality of meat being replaced. Moreover, replacing the energy induced by beef by instead consuming vegetables such as broccoli is difficult and requires large intakes which yield similarly high GHGE as beef (see online 'Supplementary material 2', Table S3). Thus, there are inherent difficulties in implementing dietary guidelines which adhere to all the principles of sustainable diets.

Typically, diets which are in accordance with health and nutrition guidelines for fruit and vegetables often conflate in reducing dietary $\mathrm{GHGE}^{(21,22)}$. Evidently, low dietary emissions were generated through the consumption of fruits and vegetables in the present study. High-sugar snacks were the second highest contributor to energy intake in the diet while also providing the least amount of GHGE per unit of energy provided. Indeed, many of the food groups which had the lowest emission factors are not conducive to good health if consumed excessively. Minimising dietary GHGE by only consuming foods low in GHGE therefore does not necessarily conform to maximising human health outcomes ${ }^{(31)}$. For instance, from a public heath perspective, increased and overconsumption of high-sugar foods may lead to negative health outcomes while concurrently resulting in lower $\mathrm{GHGE}^{(69)}$. In addition, meat was the highest source of dietary emissions but had a low energy profile. Recommendations to reduce red meat will result in reductions in GHGE but consideration must also be given to its health properties. In contrast, high-sugar snacks were low in GHGE but high in energy content; they also lack nutritional quality. Therefore, when devising low-carbon diets a balance is warranted as to both the nutritional and environmental impacts of certain food groups ${ }^{(70,71)}$. Green et $a{ }^{(22)}$ suggest that dietary emissions could be reduced 
by as much as $40 \%$ through dietary changes. However, consumers are often unwilling or unsuccessful in altering dietary behaviour ${ }^{(72)}$. Indeed, campaigns over numerous decades calling for increased intakes of fruits and vegetables have been largely unsuccessful despite active targeting by government and health organisations ${ }^{(73)}$. The advocates of meat-free diets may therefore be met with resistance as consumers favour diets that contain some meat ${ }^{(74,75)}$. 'Less but better' and 'less and more varied' meat consumption have been subsequently proposed as a dietary mitigation strategy which may appeal to consumers $^{(76)}$. Meat can be defined as 'better' if it achieves a spectrum of outcomes for climate change, the environment, animal welfare, human health, livelihoods, social justice and social values ${ }^{(77)}$. However, consumers often find ways of disengaging from many of the issues concerning meat consumption by 'explaining away' their behaviour through blame avoidance ${ }^{(75,78)}$.

There are many alternative non-voluntary measures which could be enforced to lower dietary emissions. Decreasing dietary emissions can be achieved by using economic (e.g. Pigouvian tax), social (e.g. educational campaigns) and legal instruments. Many arguments have been made in favour of a meat consumption tax, rather than a meat production $\operatorname{tax}^{(79-81)}$. It has even been suggested by Chatham House that without government intervention consumers are unlikely to reduce their consumption of animal-based produce ${ }^{(62)}$. However, consumers generally respond unfavourably to such taxation measures and there is likely to be some public resistance to a meat tax ${ }^{(82)}$. Conversely, a Finnish Mandatory Vegetarian Day is an example of a legal instrument to stimulate reduced meat consumption. A weekly forced food restriction day is implemented in the Helsinki School District whereby meat and fish have been eliminated from the school menu. The effectiveness of the intervention is unclear however and may have unintended consequences such as increased food waste arising from a hedonic dislike of vegetarian food ${ }^{(83)}$.

Sustainability can be an important motivator of behaviour and may be adopted in future campaigns to change dietary patterns and promote health ${ }^{(84)}$. Hence, policy makers, nutritionists and health professionals need to increase the public's awareness not only of health but also emphasise the environmental impact of dietary choices ${ }^{(85)}$. This may however prove challenging, considering the limited success that health organisations have had in changing consumers' behaviour towards fruit and vegetable consumption ${ }^{(73)}$. Although some subsets of individuals are motivated to eat less meat as it appeals to their psychological desires to protect the environment and promote good health, this motivation is not shared by all $^{(86)}$. Nevertheless, de Boer et $a l^{(85)}$ found that consumers' willingness to eat less meat increased with its perceived effectiveness in reducing dietary emissions. This highlights the importance of social instruments such as education and consumer awareness campaigns. Improving understanding is difficult when one considers consumers lack of awareness of GHGE generated through diet ${ }^{(85)}$. Motivating people to change embedded and habitual food behaviour is compounded by a reluctance within government, industry and even non-government organisations to inform consumers of the climatic impact of diet $^{(87)}$. Moreover, findings from a recent Eurobarometer study have shown that for consumers in Ireland climate change is not deemed as serious an issue as in other EU member states ${ }^{(88)}$. Asking individuals to trade perceived enjoyment and tradition for sustainability is challenging when the benefits of sustainability are poorly understood. Although $60 \%$ of Irish adults perceive sustainability as being important in the food choices they make, only $34 \%$ fully understand the concept ${ }^{(89)}$.

The climatic burden that accumulates throughout the food system could be potentially lowered not only by altering dietary patterns but also through changing other consumer behaviours. Towards the end of the food chain, consumers throw away food, let it spoil or engage in behaviours which contribute to unnecessary food waste. In Europe, this translates to between 95 and $115 \mathrm{~kg}$ of food waste per capita annually ${ }^{(90)}$. Food loss, on the other hand, occurs earlier in the food system. Lowering food waste and food loss represents a potentially effective method to reduce dietary $\mathrm{GHGE}^{(42)}$. Approximately one-third of the food produced globally for human consumption is lost or wasted ${ }^{(90)}$, with as much as $40 \%$ of food lost and wasted in the industrialised world occurring at retail and consumer levels ${ }^{(91)}$. If food waste can be reduced the climatic impact of dietary patterns could be considerably lowered. Furthermore, mitigation measures which address food waste, rather than consumption, may receive less resistance from consumers than other $\operatorname{actions}^{(82)}$.

Consumption of animal-based foods has been linked to both positive and negative health outcomes and there are many contrasting arguments both for and against the consumption of red meat ${ }^{(92)}$. While research has associated red meat consumption with negative health impacts ${ }^{(93)}$, other studies suggest it can have many beneficial health outcomes ${ }^{(94,95)}$. Nevertheless, it is important to note that many of the micronutrients derived from meat can also be acquired from consumption of plant-based foods ${ }^{(96,97)}$. Yet consumers' reluctance to alter their behaviour with regard to meat consumption may hinder the potential environmental benefits of a more plant-based diet. Therefore, placing the onus on the supply chain to reduce GHGE is of particular importance. Mitigation strategies that occur before the farm gate could theoretically lower emissions associated with consumption of animal products. Reductions in the carbon footprint of red meat at farm level can be as high as $30 \%$ if all producers in any given system, region and climate adopt the efficiency practices implemented by those with the 
lowest GHGE per unit of production ${ }^{(17,98)}$. Moreover, other on-farm mitigation measures could lower emissions further ${ }^{(99)}$. Ireland has implemented a sustainable food programme which enables farmers and producers to set and achieve sustainability targets by providing a framework to deliver long-term improvements in areas such as emissions mitigation with the aim of reducing GHGE associated with food production ${ }^{(100)}$. However, some research suggests that these production mitigation options alone are unlikely to be sufficient; changes in diets are also required to meet EU emission targets ${ }^{(101)}$.

Emission factors should ideally account for where food was produced, processed, distributed, etc. Thus a full understanding of the source and supply chain for each food consumed in NANS would be necessary to give an absolute and accurate estimate of dietary emissions. Nevertheless, the methods used in the present study provide a good indicator of GHGE associated with food consumption in Ireland. Indeed, the primary method to appraise dietary emissions in this research area is through sourcing emission factors from the literature rather than ones which are country specific. However, this may be limiting when assigning emission factors to foods with a high carbon footprint that may not be fully applicable in an Irish context. Globally, animal-based foods have considerable variations in emission factor estimates due to differences in methods applied and variation in agricultural production systems ${ }^{(11)}$. This was highlighted in the dairy emission factors applied from Finnegan et al. ${ }^{(43)}$, which were lower than those used in other studies. Indeed, a sensitivity analysis revealed that a $20 \%$ decrease in the emission factors used for animal-based products would lead to a $10 \%$ overall decrease in the dietary emissions elicited in the present study (see online 'Supplementary material 2', Table S1). It would not be unreasonable to assume other emission factors could also be lower than the ones found in the literature when one considers the highly competitive Irish agricultural sector and low food miles associated with Ireland's relatively small land area. Taking account of such factors in the future could result in lowering daily Irish dietary emissions.

\section{Conclusion}

Food consumption represents a substantial source of anthropogenic GHGE. Therefore it is important to quantify emissions associated with food consumption. Using detailed and reliable habitual food consumption data from a nationally representative sample of Irish adults and appropriate emission factors taken from the literature, the mean daily dietary emissions of the Irish population was calculated as $6.5 \mathrm{~kg} \mathrm{CO} \mathrm{CO}_{2}$ eq. Availability of sociodemographic and socio-economic variables supported further analysis. With the exception of education, those who had significantly higher dietary emissions per unit of energy also had significantly higher food intakes than their counterparts of similar sociodemographic and socioeconomic profiles. Thus they contributed to higher GHGE as a result of both the volume and type of food they consumed. This indicates that strategies that change food consumption patterns as well as reduce consumption could be leveraged to reduce GHGE. In Ireland, the main contributors to daily emissions were foods of animal origin; most notably foods derived from ruminant animals. Red meat provided the greatest proportion of GHGE per energy intake while high-sugar snacks provided the lowest. From a policy perspective, however, it is not a question of simply reducing meat consumption and increasing high-sugar snacks, as overconsumption of highsugar snacks while both under- and overconsumption red meat can lead to negative health outcomes. This highlights the complex relationship between diet, health and the environment. In addition, considerable challenges are involved in altering dietary behaviour as consumers are often reluctant to voluntarily alter their diets and many are unaware of the relationship between diet and climate change ${ }^{(75,85)}$. Policy interventions using economic, social and/or legal instruments targeted at consumers could however be considered in an effort to decrease dietary emissions ${ }^{(102)}$. A reduction in dietary emissions could also be realised through policy initiatives targeted at reducing food waste at the end of the chain and emissions at the start of the chain. Ireland thus has a range of voluntary, non-voluntary and alternative measures that it needs to evaluate in designing a sustainability framework to guide action in food and nutrition policy development while reducing dietary emissions from $6.5 \mathrm{~kg} \mathrm{CO}_{2} \mathrm{eq} / \mathrm{d}$ per capita.

\section{Acknowledgements}

Acknowledgements: The authors would like to thank the Irish Universities Nutritional Alliance for access to the original NANS data and all of those who took part in the survey. Financial support: This study was funded by the Department of Agriculture Food and the Marine through the Food Institutional Research Measure (FIRM) funding instrument (grant number 13/F/527). The funder had no role in the design, analysis or writing of this article. Conflict of interest: None. Authorship: J.J.H. undertook data analysis, reviewed the literature and contributed towards the writing of the manuscript. S.N.McC. advised on the objectives and design of the study and contributed towards the analysis, interpretation of the findings and writing of the manuscript. Both M.H. and M.McC. contributed towards the writing and reviewing of the manuscript. Etbics of buman subject participation: This study was conducted according to the guidelines laid down in the Declaration of Helsinki and all procedures 
involving human subjects were approved by the University of Nottingham Medical School Ethics Committee. Ethical approval for the survey was granted by the University College Cork Clinical Research Ethics Committee of the Cork Teaching Hospitals and written informed consent was obtained from study participants.

\section{Supplementary material}

To view supplementary material for this article, please visit http://dx.doi.org/10.1017/S1368980016002573

\section{References}

1. Joyce A, Hallett J, Hannelly T et al. (2014) The impact of nutritional choices on global warming and policy implications: examining the link between dietary choices and greenhouse gas emissions. Energy Emiss Control Technol issue 2, 33-43.

2. Buttriss JL (2011) Feeding the planet: an unprecedented confluence of pressures anticipated. Nutr Bull 36, 235-241.

3. Macdiarmid JI (2013) Is a healthy diet an environmentally sustainable diet? Proc Nutr Soc 72, 13-20.

4. Environmental Protection Agency of Ireland (2014) Ireland's Provisional Greenbouse Gas Emissions in 2013. Wexford: EPA.

5. Department of Environment Community and Local Government (2015) Climate Action and Low Carbon Development Bill 2015. Dublin: DECLG.

6. European Commission (2011) Communication From the Commission to the European Parliament, the Council, the European Economic and Social Committee and the Committee of the Regions 'A Roadmap for Moving to a Competitive Low Carbon Economy in 2050'. COM(2011) 112 Final. http://eur-lex.europa.eu/legal-content/EN/TXT/? uri=CELEX:52011DC0112 (accessed September 2016).

7. European Council (2010) Conclusions of the European Council. EUCO 7/10. CO EUR 4. CONCL 1 (March). http:// www.consilium.europa.eu/uedocs/cms_data/docs/press data/en/ec/113591.pdf (accessed September 2016).

8. Röös E, Karlsson H, Witthöft C et al. (2015) Evaluating the sustainability of diets - combining environmental and nutritional aspects. Environ Sci Policy 47, 157-166.

9. Audsley E, Brander M, Chatterton J et al. (2010) How Low Can We Go? An Assessment of Greenhouse Gas Emissions from the UK Food System and the Scope Reduction by 2050. London: Food Climate Research Network.

10. Food and Agriculture Organization of the United Nations (2016) Plates, Pyramids, Planet. Developments in National Healthy and Sustainable Dietary Guidelines: A State of Play Assessment. Rome: FAO.

11. Röös E, Sundberg C \& Hansson P-A (2014) Carbon footprint of food products. In Assessment of Carbon Footprint in Different Industrial Sectors, vol. 1, pp. 85-112. [SS Muthu, editor]. Singapore: Springer.

12. Liu T, Wang Q \& Su B (2016) A review of carbon labeling: standards, implementation, and impact. Renew Sustain Energy Rev 53, 68-79.

13. Baumann H \& Tillman A-M (2004) The Hitch Hiker's Guide to LCA. An Orientation in Life Cycle Assessment Methodology and Application. Lund: Studentlitteratur.

14. British Standards Institution (2008) PAS 2050:2008. Specification for the Assessment of the Life Cycle Greenhouse Gas Emissions of Goods and Services. London: BSI.
15. Auestad N \& Fulgoni VL (2015) What current literature tells us about sustainable diets: emerging research linking dietary patterns, environmental sustainability, and economics. Adv Nutr 6, 19-36.

16. Garnett $\mathrm{T}$ (2011) Where are the best opportunities for reducing greenhouse gas emissions in the food system (including the food chain)? Food Policy 36, Suppl. 1, S23-S32.

17. Gerber PJ, Steinfeld H, Henderson B et al. (2013) Tackling Climate Change Through Livestock: A Global Assessment of Emissions and Mitigation Opportunities. Rome: FAO.

18. Intergovernmental Panel on Climate Change (2007) Climate Change 2007: Synthesis Report. Contribution of Working Groups I, II and III to the Fourth Assessment Report of the Intergovernmental Panel on Climate Change. Geneva: IPCC.

19. Berners-Lee M, Hoolohan C, Cammack H et al. (2012) The relative greenhouse gas impacts of realistic dietary choices. Energy Policy 43, 184-190.

20. Carlsson-Kanyama A \& González AD (2009) Potential contributions of food consumption patterns to climate change. Am J Clin Nutr 89, issue 5, 1704S-1709S.

21. Macdiarmid JI, Kyle J, Horgan GW et al. (2012) Sustainable diets for the future: can we contribute to reducing greenhouse gas emissions by eating a healthy diet? Am J Clin Nutr 96, 632-639.

22. Green R, Milner J, Dangour AD et al. (2015) The potential to reduce greenhouse gas emissions in the UK through healthy and realistic dietary change. Clim Change 129, 253-265.

23. Food and Agriculture Organization of the United Nations (2010) Sustainable Diets and Biodiversity: Directions and Solutions for Policy, Research and Action. Rome: FAO.

24. Friel S, Dangour AD, Garnett T et al. (2009) Public health benefits of strategies to reduce greenhouse-gas emissions: food and agriculture. Lancet 374, 2016-2025.

25. Johnston JL, Fanzo JC \& Cogill B (2014) Understanding sustainable diets: a descriptive analysis of the determinants and processes that influence diets and their impact on health, food security, and environmental sustainability. Adv Nutr 5, 418-429.

26. Heller MC, Keoleian GA \& Willett WC (2013) Toward a life cycle-based, diet-level framework for food environmental impact and nutritional quality assessment: a critical review. Environ Sci Technol 47, 12632-12647.

27. van Dooren C, Marinussen M, Blonk H et al. (2014) Exploring dietary guidelines based on ecological and nutritional values: a comparison of six dietary patterns. Food Policy 44, 36-46.

28. Tukker A, Goldbohm RA, de Koning A et al. (2011) Environmental impacts of changes to healthier diets in Europe. Ecol Econ 70, 1776-1788.

29. Saxe H, Larsen TM \& Mogensen L (2012) The global warming potential of two healthy Nordic diets compared with the average Danish diet. Clim Change 116, 249-262.

30. Vieux F, Darmon N, Touazi D et al. (2012) Greenhouse gas emissions of self-selected individual diets in France: changing the diet structure or consuming less? Ecol Econ 75, 91-101.

31. Vieux F, Soler L-G, Touazi D et al. (2013) High nutritional quality is not associated with low greenhouse gas emissions in self-selected diets of French adults. Am J Clin Nutr 97, 569-583.

32. Masset G, Vieux F, Verger EO et al. (2014) Reducing energy intake and energy density for a sustainable diet: a study based on self-selected diets in French adults. Am J Clin Nutr 99, 1460-1469.

33. Scarborough P, Appleby PN, Mizdrak A et al. (2014) Dietary greenhouse gas emissions of meat-eaters, 
fish-eaters, vegetarians and vegans in the UK. Clim Change 125, 179-192.

34. Hoolohan C, Berners-Lee M, McKinstry-West J et al. (2013) Mitigating the greenhouse gas emissions embodied in food through realistic consumer choices. Energy Policy 63, 1065-1074.

35. Temme EHM, Toxopeus IB, Kramer GFH et al. (2015) Greenhouse gas emission of diets in the Netherlands and associations with food, energy and macronutrient intakes. Public Health Nutr 18, 2433-2445.

36. Food and Agriculture Organization of the United Nations (2002) Individual Food Intake Survey Methods. Rome: FAO.

37. Black AE (2000) Critical evaluation of energy intake using the Goldberg cut-off for energy intake:basal metabolic rate. A practical guide to its calculation, use and limitations. Int J Obes Relat Metab Disord 24, 1119-1130.

38. Goldberg GR, Black AE, Jebb SA et al. (1991) Critical evaluation of energy intake data using fundamental principles of energy physiology: 1 . Derivation of cut-off limits to identify under-recording. Eur J Clin Nutr 45, 569-581.

39. Irish Universities Nutrition Alliance (2011) National Adult Nutrition Survey: Summary Report. http://www.iuna.net/ wp-content/uploads/2010/12/National-Adult-NutritionSurvey-Summary-Report-March-2011.pdf (accessed May 2016).

40. Naughton P, McCarthy SN \& McCarthy MB (2015) The creation of a healthy eating motivation score and its association with food choice and physical activity in a cross sectional sample of Irish adults. Int J Behav Nutr Phys Act 12, 74.

41. Heller MC \& Keoleian GA (2015) Greenhouse gas emission estimates of US dietary choices and food loss. $J$ Ind Ecol 19, 391-401.

42. Venkat K (2011) The climate change and economic impacts of food waste in the United States. Int J Food Syst Dyn 2, 431-446.

43. Finnegan W, Goggins J, Clifford E et al. (2015) Global warming potential associated with dairy products in the Republic of Ireland. J Clean Prod (Epublication ahead of print version).

44. Pradhan P, Reusser DE \& Kropp JP (2013) Embodied greenhouse gas emissions in diets. PLoS One 8, e62228.

45. Lumley T, Diehr P, Emerson S et al. (2002) The importance of the normality assumption in large public health data sets. Annu Rev Public Health 23, 151-169.

46. Aston LM, Smith JN \& Powles JW (2012) Impact of a reduced red and processed meat dietary pattern on disease risks and greenhouse gas emissions in the UK: a modelling study. BMJ Open 2, e001072.

47. Macdiarmid J, Kyle J, Horgan G et al. (2011) Livewell: A Balance of Healthy and Sustainable Food Choices. Woking: World Wildlife Fund.

48. Wilson N, Nghiem N, Ni Mhurchu C et al. (2013) Foods and dietary patterns that are healthy, low-cost, and environmentally sustainable: a case study of optimization modeling for New Zealand. PLoS One 8, e59648.

49. Risku-Norja H, Kurppa S \& Helenius J (2010) Dietary choices and greenhouse gas emissions - assessment of impact of vegetarian and organic options at national scale. Prog Ind Ecol 6, 340-354.

50. Fazeni K \& Steinmüller H (2011) Impact of changes in diet on the availability of land, energy demand, and greenhouse gas emissions of agriculture. Energy Sustain SOC 1, 6.

51. Eshel G \& Martin PA (2006) Diet, energy, and global warming. Earth Interact 10, 1-17.

52. Popp A, Lotze-Campen H \& Bodirsky B (2010) Food consumption, diet shifts and associated non- $\mathrm{CO}_{2}$ greenhouse gases from agricultural production. Glob Environ Change 20, 451-462.
53. French Agency for Food, Environmental and Occupational Health and Safety (2014) Detailed results of the INCA 2 study. https://www.anses.fr/en/content/detailed-resultsinca-2-study (accessed June 2016).

54. van Rossum CTM, Fransen HP, Verkaik-Kloosterman J et al. (2011) Dutch National Food Consumption Survey 2007-2010. Bilthoven: National Institute for Public Health and the Environment (RIVM).

55. Newcombe MA, McCarthy MB, Cronin JM et al. (2012) 'Eat like a man'. A social constructionist analysis of the role of food in men's lives. Appetite 59, 391-398.

56. Cronin JM, McCarthy MB, Newcombe MA et al. (2014) Paradox, performance and food: managing difference in the construction of femininity. Consum Mark Cult 17, 367-391.

57. El Ansari W, Sebena R \& Stock C (2013) Sociodemographic correlates of six indicators of alcohol consumption: survey findings of students across seven universities in England, Wales and Northern Ireland. Arch Public Health 71, 29.

58. El Ansari W, Stock C \& Mikolajczyk RT (2012) Relationships between food consumption and living arrangements among university students in four European countries - a cross-sectional study. Nutr J 11, 28.

59. Smith J, Sones K, Grace D et al. (2012) Beyond milk, meat, and eggs: role of livestock in food and nutrition security. Anim Front 3, 6-13.

60. Laestadius LI, Neff RA, Barry CL et al. (2014) No meat, less meat, or better meat: understanding NGO messaging choices intended to alter meat consumption in light of climate change. Environ Commun 10, 84-103.

61. World Resourse Institute (2016) Shifting Diets for a Sustainable Food Future. London: WRI.

62. Chatham House (2015) Changing Climate, Changing Diets Pathways to Lower Meat Consumption. London: Chatham House.

63. Tom MS, Fischbeck PS \& Hendrickson CT (2015) Energy use, blue water footprint, and greenhouse gas emissions for current food consumption patterns and dietary recommendations in the US. Environ Syst Decis 36, 92-103.

64. Meier T \& Christen O (2013) Environmental impacts of dietary recommendations and dietary styles: Germany as an example. Environ Sci Technol 47, 877-888.

65. Vanham D, Mekonnen MM \& Hoekstra AY (2013) The water footprint of the EU for different diets. Ecol Indic 32, $1-8$.

66. Vanham D (2013) The water footprint of Austria for different diets. Water Sci Technol 67, 824-830.

67. Hallström E, Carlsson-Kanyama A \& Börjesson P (2015) Environmental impact of dietary change: a systematic review. J Clean Prod 91, 1-11.

68. Food Standards Agency (2015) McCance and Widdowson's The Composition of Foods, Seventh Summary Edition. London: Royal Society of Chemistry.

69. Yang Q, Zhang Z, Gregg EW et al. (2014) Added sugar intake and cardiovascular diseases mortality among US adults. JAMA Intern Med 174, 516-524.

70. Tilman D \& Clark M (2014) Global diets link environmental sustainability and human health. Nature $\mathbf{5 1 5}$, $518-522$

71. Briggs ADM, Kehlbacher A, Tiffin R et al. (2013) Assessing the impact on chronic disease of incorporating the societal cost of greenhouse gases into the price of food: an econometric and comparative risk assessment modelling study. BMJ Open 3, e003543.

72. Chance Z, Gorlin M \& Dhar R (2014) Why choosing healthy foods is hard, and how to help: presenting the 4Ps framework for behavior change. Cust Needs Solut 1, 253-262. 
73. Rekhy R \& McConchie R (2014) Promoting consumption of fruit and vegetables for better health. Have campaigns delivered on the goals? Appetite 79, 113-123.

74. Schösler H, de Boer J \& Boersema JJ (2012) Can we cut out the meat of the dish? Constructing consumer-oriented pathways towards meat substitution. Appetite 58, 39-47.

75. Graça J, Calheiros MM \& Oliveira A (2015) Attached to meat? (Un)Willingness and intentions to adopt a more plant-based diet. Appetite 95, 113-125.

76. de Boer J, Schösler H \& Aiking H (2014) 'Meatless days' or 'less but better'? Exploring strategies to adapt Western meat consumption to health and sustainability challenges. Appetite 76, 120-128.

77. Sutton C \& Dibb S (2013) Prime Cuts: Valuing the Meat We Eat. Woking: World Wildlife Fund.

78. Rothgerber H (2014) Efforts to overcome vegetarianinduced dissonance among meat eaters. Appetite 79, 32-41.

79. Edjabou LD \& Smed S (2013) The effect of using consumption taxes on foods to promote climate friendly diets - the case of Denmark. Food Policy 39, 84-96.

80. Nordgren A (2011) Ethical issues in mitigation of climate change: the option of reduced meat production and consumption. J Agric Environ Ethics 25, 563-584.

81. Wirsenius S, Hedenus F \& Mohlin K (2010) Greenhouse gas taxes on animal food products: rationale, tax scheme and climate mitigation effects. Clim Change 108, 159-184.

82. Vanhonacker F, Van Loo EJ, Gellynck X et al. (2013) Flemish consumer attitudes towards more sustainable food choices. Appetite 62, 7-16.

83. Lombardini C \& Lankoski L (2013) Forced choice restriction in promoting sustainable food consumption: intended and unintended effects of the mandatory vegetarian day in Helsinki Schools. J Consum Policy 36, 159-178.

84. Clonan A, Wilson P, Swift JA et al. (2015) Red and processed meat consumption and purchasing behaviours and attitudes: impacts for human health, animal welfare and environmental sustainability. Public Health Nutr 18, 2446-2456.

85. de Boer J, de Witt A \& Aiking H (2015) Help the climate, change your diet: a cross-sectional study on how to involve consumers in a transition to a low-carbon society. Appetite 98, 19-27.

86. Schösler H, de Boer J \& Boersema JJ (2014) Fostering more sustainable food choices: can self-determination theory help? Food Qual Prefer 35, 59-69.

87. Laestadius LI, Neff RA, Barry CL et al. (2014) 'We don't tell people what to do': an examination of the factors influencing NGO decisions to campaign for reduced meat consumption in light of climate change. Glob Environ Change 29, 32-40.

88. European Commission (2014) Special Eurobarometer 409: Climate Change. Brussels: EC.

89. Periscope (2015) Irish \& British Consumers \& Their Food. Dublin: Bord Bia.

90. Food and Agriculture Organization of the United Nations (2016) Key facts on food loss and waste you should know! http://www.fao.org/save-food/resources/ keyfindings/en/ (accessed February 2016).
91. Food and Agricultural Organization of the United Nations (2011) Global Food Losses and Food Waste: Extent, Causes and Prevention. Rome: FAO.

92. McAfee AJ, McSorley EM, Cuskelly GJ et al. (2010) Red meat consumption: an overview of the risks and benefits. Meat Sci 84, 1-13.

93. Boada LD, Henríquez-Hernández LA \& Luzardo OP (2016) The impact of red and processed meat consumption on cancer and other health outcomes: epidemiological evidences. Food Chem Toxicol 92, 236-244.

94. Binnie MA, Barlow K, Johnson V et al. (2014) Red meats: time for a paradigm shift in dietary advice. Meat Sci $\mathbf{9 8}$, 445-451.

95. De Smet S \& Vossen E (2016) Meat: the balance between nutrition and health. A review. Meat Sci $\mathbf{1 2 0}$, 145-156.

96. Temme EHM, van der Voet H, Thissen JTNM et al. (2013) Replacement of meat and dairy by plant-derived foods: estimated effects on land use, iron and SFA intakes in young Dutch adult females. Public Health Nutr 16 1900-1907.

97. McEvoy CT, Temple N \& Woodside JV (2012) Vegetarian diets, low-meat diets and health: a review. Public Health Nutr 15, 2287-2294.

98. Hyland JJ, Styles D, Jones DL et al. (2016) Improving livestock production efficiencies presents a major opportunity to reduce sectoral greenhouse gas emissions. Agric Syst 147, 123-131.

99. Schader C, Muller A, Scialabba NE-H et al. (2015) Impacts of feeding less food-competing feedstuffs to livestock on global food system sustainability. $J R$ Soc Interface $\mathbf{1 2}$ doi:10.1098/rsif.2015.0891.

100. Bord Bia (2015) Origin Green: Sustainability Report 2015. Dublin: Bord Bia.

101. Bryngelsson D, Wirsenius S, Hedenus F et al. (2016) How can the EU climate targets be met? A combined analysis of technological and demand-side changes in food and agriculture. Food Policy 59, 152-164.

102. Vranken L, Avermaete T, Petalios D et al. (2014) Curbing global meat consumption: emerging evidence of a second nutrition transition. Environ Sci Policy 39, 95-106.

103. Cosgrove M, Flynn A \& Kiely M (2007) Consumption of red meat, white meat and processed meat in Irish adults in relation to dietary quality. $B r J$ Nutr $\mathbf{9 3}$, 933-942.

104. Cosgrove M, Flynn A \& Kiely M (2007) Impact of disaggregation of composite foods on estimates of intakes of meat and meat products in Irish adults. Public Health Nutr 8, 327-337.

105. Baghurst K, Record S \& Leppard P (2000) Red meat consumption in Australia: intakes, nutrient contribution and changes over time. Aust J Nutr Diet 57, Suppl. 4, S1-S36.

106. Hendrie GA, Ridoutt BG, Wiedmann TO et al. (2014) Greenhouse gas emissions and the Australian diet comparing dietary recommendations with average intakes. Nutrients 6, 289-303. 